\title{
Desenvolvimento De Uma Ferramenta De Precificação Para Jogos De Futebol
}

\section{A Pricing Tool Development for Football Tickets}

Rodolfo Ribeiro (dolfo.ribeiro@gmail.com) - Faculdade de Tecnologia Sebrae (Fatec), Brasil

\section{RESUMO}

A demanda de uma organização depende de fatores do ambiente e de sua competitividade, sendo o peso desses fatores muito diferente de acordo com a estrutura de mercado enfrentada pela organização. Neste artigo, foi analisada a previsão de demanda em um clube de futebol e, na literatura pesquisada sobre o objeto estudado, notou-se uma predominância do uso da regressão como método para explicar o comportamento da demanda. Nos trabalhos pesquisados, foram utilizadas bases de dados com a demanda de diversos clubes (empresas) de forma conjunta. Contudo, como cada clube é monopolista de sua demanda (devido à alta fidelidade de seu público consumidor), o conhecimento da função de demanda de cada clube permite uma definição de preços que extraia maior excedente do consumidor quando este for o interesse do clube. O objetivo deste artigo é apresentar o desenvolvimento de uma solução de precificação de ingressose de previsão de demanda para um clube de futebol. A extrema variabilidade dos dados (desvio padrão elevado) e a relação entre as variáveis de um jogo trazem desafios para a definição de preços, pois no histórico de jogos os maiores públicos foram obtidos com os maiores preços, o que contraria a lei geral da demanda. Metodologicamente, o modelo de regressão gerado leva em consideração a importância (i) de cada partida, estimada considerando o melhor ajuste entre a relação de preço, importância e público para um total de 302 partidas analisadas. O modelo final conta com doze valores de i diferentes, além de mais dez variáveis independentes e seu $\mathrm{r}^{2}$ apresentou sensível melhora em relação à bibliografia pesquisada. As contribuições para a gestão no objeto pesquisado são inúmeras: melhor dimensionamento de quadro de funcionários e despesas operacionais, a implementação de incentivos mais adequados ao aumento de público e uma maior assertividade em transferência de mando de jogos.

Palavras-chave: Previsão de Demanda, Precificação, Futebol. 


\section{ABSTRACT}

An organization's demand depends on the environment conditions and its competitiveness, and the measure that each one affects the company's demand is related to the market structure faced by the organization. In this article, it was analyzed the demand forecast for a soccer club's tickets and, in the researched literature, regression models seemed to be mainly used to explain the demand variation in this product. Usually, researches focused on soccer ticket's demand using databases with several clubs being simultaneously analyzed. However, each club is a monopolist of its own demand (due to high loyalty of fans/consumers) and knowing how demands respond in each club allows better price definition, extracting consumer surplus when necessary. The goal of this paper is to present a pricing tool development and demand forecast for a soccer club. High variability (elevated standard deviation) and relationship among variables bring a lot of challenges to pricing definition for soccer tickets, due to higher demand associated with higher prices, contradicting the expected demand function. Methodologically, generated regression model uses each match importance (i), estimated considering the best fit between price, importance and publicfor a database composed of 302 matches. Final model uses twelve (i) different values and ten other independent variables and its $r^{2}$ presented improvement compared to the researched literature. Contributions to management goes from better forecasting expenses related to match operation (employees and other services), better incentives to raise demand and higher assertiveness in transferring matches to other stadium or city.

Keywords: Demand Forecasting, Pricing, Football.

\section{INTRODUÇÃO}

Segundo pesquisa do Ministério do Esporte (2017), o esporte mais popular no Brasil é o futebol e essa preferência nacional foi originada na década de 1920 (Deloitte, 2011; Fujita, 2018). Diversos autores destacam o papel desse esporte na cultura brasileira, como Damo (2018) e Damatta (1994). Além de seu papel cultural, há o lado econômico do futebol brasileiro. Notório exportador de jogadores (Alvito, 2006; Rodrigues, 2010), os principais clubes do país possuem faturamentos que os colocariam entre grandes empresas. $\mathrm{Na}$ perspectiva econômica mundial, os vinte maiores clubes em faturamento cresceram, de 97 à 2018, 9,6\% em média no volume total de suas receitas (Deloitte, 2019). Os clubes de maior faturamento no 
mundo em 2018, por exemplo, arrecadaram 8,3 bilhões de euros (Deloitte, 2019). No Brasil, o clube de maior faturamento no ano de 2017 - Clube de Regatas Flamengo - arrecadou R\$ 595 milhões (ltaú BBA, 2018), bastante abaixo da maior arrecadação mundial, de $€$ 750,9 milhões, obtida pelo espanhol Real Madrid (Deloitte, 2019). Ainda que em 2019 o clube de maior arrecadação no Brasil tenha obtido uma receita de R\$ 841 milhões (ltaú BBA, 2020), os valores permanecem bastante inferiores aos obtidos na Europa.

Para movimentar suas receitas, os clubes possuem algumas fontes principais de receita: bilheteria, direitos de transmissão dos jogos, venda de jogadores e demais receitas de exploração de produtos e serviços (Deloitte, 2019). Em nível mundial, descontadas as receitas de vendas de jogadores (menos previsíveis), a receitas de bilheteria equivalem à $17 \%$ do volume arrecadado pelos clubes. Já no Brasil, o montante equivalente à bilheteria correspondeu à 15\% em 2017 (Deloitte 2019; Itau BBA, 2018).

Segundo Ekelund (1998), a representatividade dessas receitas se alterou ao logo do tempo, devido aos diversos aspectos de macroambiente que mudaram ao longo do tempo, fazendo com que a importância de certos stakeholders variasse bastante. Apesar dessas alterações, pode-se afirmar que a receita adquirida com a venda de ingressos dependerá, majoritariamente, de alguns fatores, tais como:

- capacidade de oferta do clube (capacidade do estádio onde mandaseusjogos);

- quantidade de jogos realizados;

- tamanho de sua torcida;

- interesse da torcida em acompanhar os jogos.

Esses fatores tendem a variar de forma muito diferente no curto e longo prazo. A capacidade de oferta só se altera mediante reformas nos estádios ou construção de novos equipamentos, com considerável investimento em sua construção. A quantidade de jogos em cada temporada tende a ser 
previsível, com exceção de campeonatos com fases eliminatórias. A torcida de um clube tende a variar pouco no curto prazo, pois depende da combinação de fatores sociais e do desempenho no clube (Ribeiro, 2017).

Para maximizar público ou renda obtida nos estádios, os clubes devem, portanto, conhecer sua demanda por ingressos. Uma previsão mais assertiva de demanda e receita traz inúmeras contribuições à gestão do clube, como a redução de desperdícios causados por demanda acima do esperado ou a captura de excedentes quando a demanda aumenta de forma considerável.

Este artigo tem o objetivo de apresentar o desenvolvimento de uma solução de precificação de ingressos e de previsão de demanda para um clube de futebol. Esta solução foi desenvolvida durante uma intervenção em um clube cujo escopo envolveu a sistematização de uma política de preços de ingressos. A metodologia utilizada foi a regressão múltipla, pois o objetivo era compreender o comportamento de uma variável dependente (público pagante) em função de variáveis independentes (adversário, campeonato, preço, horário, etc). Os principais interesses do clube envolviam uma interpretação menos subjetiva de como o preço afeta o público pagante e a compreensão dos trade-offs entre ocupação máxima e receita máxima a cada jogo.

\section{REFERENCIAL TEÓRICO}

Dado o objetivo deste trabalho, o conceito fundamental que o envolve é a lei da demanda, ou seja, quanto menor o preço de um produto, maior será a quantidade demandada (Pindyck \& Rubinfeld, 2002). Dado o nível de lealdade observado nos torcedores, definidos como indivíduos com alguma ligação psicológica com uma equipe (Hunt, Bristol \& Barshaw, 1999), assume-se que cada clube é monopolista de sua demanda no curto prazo. O tamanho da torcida tende a variar de forma sensível apenas no longo prazo, dado que seu crescimento está amparado em fatores sociais e esportivos para a conversão de novos indivíduos em torcedores (Ribeiro, 2017). 
A previsão de demanda é um dos pontos centrais na gestão de uma empresa (Sampron, 2005). Isso porque toda a alocação de recursos produtivos (matéria prima e mão de obra) depende da quantidade a ser produzida e, consequentemente, vendida pela empresa. Um mau dimensionamento da demanda compromete, dessa forma, toda a alocação de recursos de uma companhia, seja no caso de excesso de demanda, gerando perda de vendas, ou no caso de excesso de capacidade, gerando perda por ociosidade (Slack; Chambers \& Johnston, 2009). Assim sendo, a escolha e uso de um método adequado de previsão de demanda é um dos pontos principais do planejamento empresarial.

Em termos gerais, pode-se compreender a demanda de uma empresa como consequência de dois fatores principais: as condições do ambiente ea atratividade de sua oferta (Sampron, 2005). Diversos materiais básicos de estratégia e marketing, como Porter (2004) e Kotler e Keller (2012) sugerem que os fatores do ambiente estão fora do controle da empresa, enquanto há uma perspectiva de que 0 ambiente pode ser influenciado pela organização (Barney, Hesterly \& Rosemberg, 2007). Em termos de curto prazo, no entanto, a preocupação da organização em relação ao planejamento de sua demanda estará mais relacionada com a atratividade de sua oferta.

\section{Abordagens de planejamento de demanda em livros de gestão}

Durante o planejamento, portanto, uma organização deverá escolher entre um método apropriado para previsão e demanda para dimensionar adequadamente seus recursos e minimizar os riscos de uma demanda superestimada ou subestimada. Os principais livros componentes das bibliografias de cursos de gestão no país são pouco úteis para a escolha de um método apropriado de previsão. A obra de Kotler e Keller (2012), por exemplo, sempre utilizada em disciplinas de marketing, é pouco específica na escolha de um método de projeção de demanda. O livro menciona a importância de um sistema de marketing que tenha informações internas e 
do ambiente. Além disso, os autores citam a diferença entre a demanda como função dos investimentos da indústria e das condições do ambiente. Como as condições do ambiente variam de forma mais lenta, com impactos de longo prazo, a demanda de curto prazo tende a ser de maior controle da organização. Os métodos citados por Kotler e Keller (2012) são: potencial total de mercado, potencial de mercado por área e indexação multifatorial. Essas variáveis, no entanto, são de difícil conhecimento por parte das empresas. Além disso, pequenas variações em potencial de mercado, por exemplo, geram enorme diferença na demanda final.

A obra de Hisrich, Peters \& Shepherd (2014), utilizada em disciplinas vinculadas ao empreendedorismo e à administração geral, tampouco elucida a questão da escolha de um método apropriado. Os autores argumentam que "para começar, o empreendedor deve pesquisar tudo o que puder sobre as outras novas empresas do seu setor" e que "mudanças de estratégia também afetam as vendas e precisam ser incluídas nas estimativas" (Hisrich, Peters \& Shepherd, 2014, p.235-236).

Nessa questão de mensuração da demanda, um livro texto comum que endereça de forma mais complexa métodos de previsão é o utilizado em disciplinas de produção e operações, como Slack, Chambers e Johnston (2009). Além de apresentar diferentes métodos, cuja abordagens podem ser qualitativas (painel, delphi e planejamento de cenários) ou quantitativas (séries temporais, média móvel, ajustamento exponencial e modelos causais), os autores discutem a aderência desses métodos no curto e no longo prazo.

Pode-se assumir, no entanto, que a demanda de mercado ou de uma empresa específica é uma função de causa-efeito, na qual as variáveis explicativas envolvem não só fatores do ambiente (poder de compra, nível de emprego e renda, etc) como também fatores da empresa (qualidade da oferta, competição, incentivos comerciais, etc). Como Slack, Chambers e Johnston (2009) sugerem, no curto prazo a inércia de variáveis do ambiente 
é grande, fazendo com que o peso de fatores específicos da empresa seja maior quando o horizonte de planejamento é curto.

Lemos (2006) divide os métodos de projeção de demanda em dois grandes grupos: qualitativos e quantitativos. Métodos qualitativos costumam utilizar julgamentos baseados na experiência de profissionais envolvidos. $O$ método Delphi, por exemplo, combina a opinião de diversas pessoas envolvidas no processo, estimulando um consenso na previsão (Slack, Chambers \& Johnston, 2009). Já métodos quantitativos adotam uma formulação matemática para a previsão. Esses métodos podem utilizar a própria demanda como fator de previsão (média móvel, por exemplo) ou adotar abordagens causais (modelos de regressão).

Outro fator a ser considerado é a especificidade do objeto de interesse na mensuração. Produtos diferentes possuem variações muito distintas em função das características específicas de sua demanda (sazonalidade, competição, elasticidade e tipo de produto - bem inferior ou superior, por exemplo). Portanto, um planejador pode escolher um método mais apropriado analisando em quais condições seu objeto de planejamento está enquadrado.

Um material que aborda diversas questões de forma a auxiliar o interessado na escolha de um método apropriado é o elaborado por Farris et al (2012). Os autores indicam que o preço ótimo a ser definido é aquele que maximiza a receita, orientando a construção de uma curva de demanda que possibilite o cálculo do preço que gere o resultado desejado. Contudo, os autores reconhecem que a determinação do preço ótimo requer o conhecimento da elasticidade e que isso só é possível mediante a estruturação de uma série de dados (preços de reserva e/ou resultados de testes de mercado). Naturalmente, esses dados envolvem um custo associado à coleta e, além disso, de sistemas e pessoas capacitadas para utilizá-los. 
Pindyck e Rubinfeld (2012), abordar a definição de preços de acordo com a estrutura de mercado, também endereçam 0 assunto com objetividade. Porém, a abordagem de acordo com as estruturas requer a correta classificação da estrutura enfrentada pela empresa e o tratamento adequado de variáveis, como destacado por Farris et al (2012).

O próximo item do referencial teórico traz contribuições de estudos realizados com o objeto de interesse nessa pesquisa, discutindo sua metodologia e resultados alcançados.

\section{Mensuração de demanda por ingressos de jogos de futebol}

Souza (2004) abordou a previsão de público do campeonato brasileiro de futebol com modelos de regressão bastante satisfatórios. O autor chegou em modelos finais bastante explicativos $\left(r^{2}=0,55\right)$, porém sem o preço como variável explicativa do público presente nos estádios. No entanto, a modelagem desenvolvida não envolvia um clube específico, e sim qualquer jogo da série principal no Brasil. Para explicação do público de todos os clubes, variáveis como renda da cidade, desemprego, atratividade do confronto e qualidade do elenco mostraram-se significantes.

Benevides et al (2015) apresenta uma análise bastante extensa de estudos de demanda relacionados ao futebol. Os autores destacam que a maioria dos trabalhos destaca que a relevância de "fatores econômicos, estruturais e de qualidade da partida são comuns nos estudos sobre a demanda por futebol" (Benevides et al, 2015, p.102).

Ribeiro et al (2015) abordou não a demanda em si, mas a intenção de compra de torcedores. Como se assume que a intenção é um razoável antecedente da compra efetiva, os resultados sugerem que rivalidade, horário e campeonato/fase, além de preço, afetam a demanda de um jogo. Além disso, os autores avaliam que a percepção de segurança desloca sensivelmente a demanda, aumentando o consumo quando o torcedor não sente percepção de risco de violência em um determinado jogo. 
Ao analisar esses trabalhos, nota-se que a preocupação dos autores esteve vinculada à explicação da demanda como um todo, e não de um clube específico. Há diversos outros trabalhos nessa linha, com resultados semelhantes aos já abordados.

Analisando cada clube individualmente, é razoável supor que o preço é variável explicativa do público. Há diversas evidências de que um jogo pode não ter tido seus ingressos esgotados por preços muito altos, conforme reportagens do Globo Esporte $(2013,2018)$. Contudo, há jogos que, mesmo com ingressos baratos, não possuem a demanda esperada (Globo Esporte, 2018). É razoável assumir, portanto, que o preço ideal varia de acordo com o jogo, sendo possível que alguns jogos tenham uma capacidade de público abaixo da capacidade do estádio.

\section{METODOLOGIA DE PESQUISA}

O objetivo deste trabalho - apresentar o desenvolvimento de uma solução de precificação de ingressos e de previsão de demanda para um clube de futebol - partiu da necessidade de um clube definer seus preços de forma sistemática, levando em consideração as múltiplas variáveis que compõem um jogo, resolvendo com isso um conflito de interesses entre as áreas envolvidas na precificação de um jogo (finanças, marketing e comunicação, principalmente).

As escolhas metodológicas derivadas desse contexto assumiram que a demanda por um jogo de um time de futebol tende a se aproximar de uma demanda enfrentada por um monopolista. Isso porque torcedores de um time não consideram comprar ingressos para acompanhar outras equipes, dado o seu nível de lealdade com a equipe previamente escolhida. Ou seja, a definição de preços de um jogo de uma equipe A não afeta a demanda por ingressos para um jogo da equipe B, pois não há intersecção entre os interessados nas partidas. 
A demanda de um bem pode ser influenciada também por efeitos renda e substituição, por exemplo (Pindyck \& Rubinfeld, 2002). Contudo, esses fatores não tendem a ser representativos de um jogo para outro (o intervalo médio entre jogos no período analisado foi de 9 dias). De acordo com McAfee (2002), há duas estratégias básicas de precificação: discriminação direta (cobrar diferente de cada consumidor, de acordo com uma característica específica) e indireta (tornar a oferta disponível para qualquer consumidor). A definição de preço de ingressos, pela legislação brasileira, impede a prática da discriminação direta. Caso o clube opte por uma oferta, deve torná-la disponível para todos os consumidores.

Iniciou-se uma análise dos jogos pregressos do clube, com um prazo de 5 anos de análise. Segundo a direção do clube, nesse período de tempo o clube oscilou bastante em termos de desempenho esportivo, disputando jogos de alto interesse e partidas de baixíssimo interesse por parte do torcedor. A tabela 1 exibe um resumo dos dados analisados.

Tabela 1 - Dados Analisados para Desenvolvimento do Modelo

\begin{tabular}{|c|c|c|}
\hline \multicolumn{2}{|l|}{ Variável } & Valor \\
\hline \multicolumn{2}{|l|}{ Jogos } & 302 \\
\hline \multicolumn{2}{|c|}{ Jogos em casa } & 151 \\
\hline \multicolumn{2}{|c|}{ Jogos fora de casa } & 151 \\
\hline \multirow{7}{*}{ Público } & Média & $24.192,2$ \\
\hline & Desvio Padrão & $15.512,3$ \\
\hline & $1^{\circ}$ Quartil & 12.408 \\
\hline & Mediana & 19.987 \\
\hline & $3^{\circ}$ Quartil - Público & $31.941,5$ \\
\hline & Mínimo - Público & 3.013 \\
\hline & Máximo - Público & 66.214 \\
\hline \multirow{6}{*}{ Ticket } & Ticket Médio & 29,6 \\
\hline & Desvio Padrão - Tickeł & 13,3 \\
\hline & $1^{\circ}$ Quartil - Ticket & 23,6 \\
\hline & $3^{\circ}$ Quartil - Ticket & 30,8 \\
\hline & Mínimo - Ticke† & 10,8 \\
\hline & Máximo-Ticke† & 121,9 \\
\hline
\end{tabular}

Pelos dados expostos na tabela 1, nota-se a extrema variabilidade da demanda (desvio-padrão elevado e 59\% dos jogos com valor abaixo da demanda média). Outra particularidade na demanda dos jogos é a relação entre preço e público. Pela lei geral da demanda (Ferguson, 1999), espera-se 
uma relação inversa entre preço e quantidade vendida de um bem. Uma análise preliminar de público pagante e preço do ingresso, no entanto, mostra que os jogos de maior público foram, em média, aqueles com maior preço de ingresso, conforme exibido no gráfico $1(r=0,22)$.

Gráfico 1 - Comparação de Quantidade Vendida e Preço

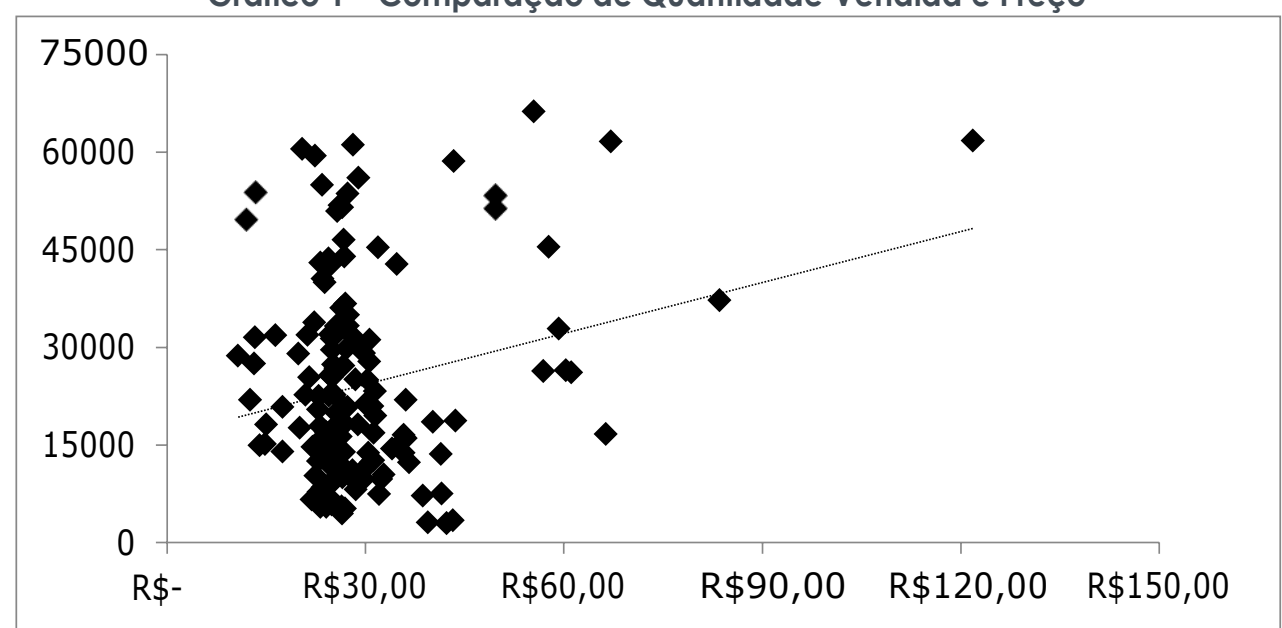

Assumindo que a lei geral da demanda se aplica nesse caso e que ingressos de um jogo não são bens de Giffen, essa relação sugere que cada jogo é visto de forma particular pelo público interessado. Consequentemente, as partidas têm valores subjetivos distintos para o torcedor. Assim, quando um jogo com ingresso "caro" (R\$ 121,85) possui público de 61.766 pagantes, pode-se assumir que este jogo está mais barato, em termos relativos, do que um jogo com ingresso à $R \$ 42,34 \mathrm{com} 3.013$ pagantes. Um dado que suporta esse raciocínio é a pesquisa de Ribeiro et al (2014), na qual a satisfação do torcedor com o desempenho de seu time depende do varia em função do que é conquistado em cada competição disputada pela equipe, tendo as competições disputadas pesos muito distintos na composição da satisfação do torcedor. Diante desses dados, as seguintes premissas teórico-conceituais foram assumidas:

pl: um modelo de definição de preços terá maior poder explicativo ao focar na demanda de um clube específico, já que cada clube é monopolista de sua demanda. Essa premissa é suportada pela característica 
particular da demanda dos clubes, formada majoritariamente por seu público torcedor. Como o torcedor raramente troca de time (Damo, 2001; Hunt, Bristol \& Barshaw, 1999), um modelo de preços analisando um clube específico tende a fornecer maior compreensão da demanda;

p2: os preços praticados por um clube devem explorar o potencial de cada jogo, permitindo ao clube a extração de excedente de demanda quando possível e pretendido. Ou seja, ao compreender a função de demanda de seu público, o clube pode escolher o quanto extrair do excedente do consumidor, optando por estratégias de receita máxima ou ocupação máxima em cada jogo.

Dada a variância dos dados, técnicas de extrapolação como média móvel e suavização exponencial não eram recomendadas (Slack, Chambers \& Johnston, 2009). Partiu-se então, para um modelo causal, no qual a maior necessidade era a interpretação do preço como uma variável componente da previsão do público. Conforme o gráfico 1 exibe, um passo anterior era necessário: a definição de um fator de valoração para cada partida. Adotou-se a premissa exposta na equação 1:

Equação 1: público pagante $=-$ preço $/ i$

Nessa equação, o público pagante dependerá da relação entre preço e importância do jogo. Assim, para jogos com o mesmo i, preços maiores diminuem o público. De forma análoga, para jogos com o mesmo i, preçosmenores aumentam o público.

A mensuração de um i apropriado envolveu a definição de que o i deveria variar de acordo com o campeonato e fase disputados. De forma simplificada, as equipes brasileiras disputam dois tipos de competição: as que envolvem jogos eliminatórios e as de pontos corridos. Para as competições de jogos eliminatórios, adotou-se que cada fase posterior é preferível à anterior (i de uma semifinal deve se superior ao i de uma fase quartas de final, por exemplo). Nas competições de pontos corridos, o i de 
um jogo com o time disputando posições mais altas na tabela deveria ter maior valor que o i de um jogo com a equipe jogando por posições intermediárias. Após esse mecanismo de ajuste do preço à demanda, a relação obtida entre demanda e preço/i se assemelhou aos dados expostos no gráfico 2.

Gráfico 2 - Comparação de Quantidade Vendida e Preço/i

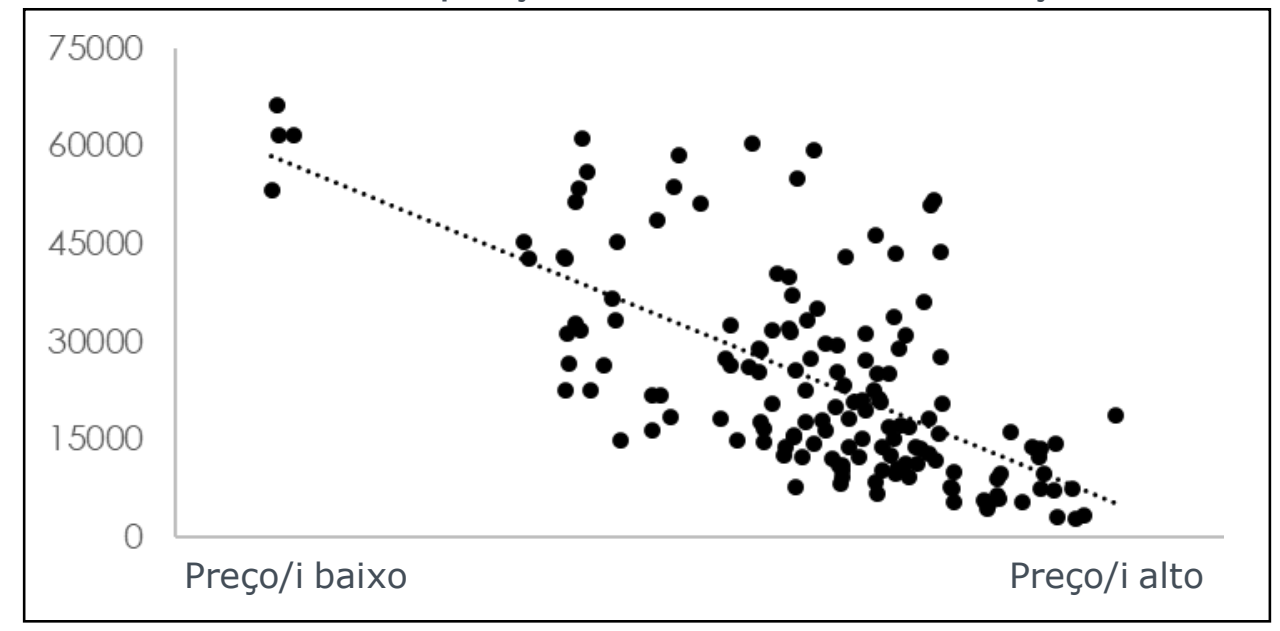

Após a obtenção de um i que invertesse a relação ingresso e público previamente observada, ajustando-a para a lei geral da semana, partiu-se para a elaboração de um modelo de regressão múltipla. As variáveis para composição do modelo foram:

- preço/i;

- horário da partida (categorizado em oito valores diferentes);

- adversário (categorizado em três valores distintos);

- desempenho esportivo (número de vitórias, saldo de gols, gols pró) em um intervalo de partidas variando de um à cinco;

- estreia de reforço contratado;

- campeonato;

- necessidade de vitória em confronto eliminatório;

- estádio no qual a partida é jogada; 
- condições de clima (chuva na cidade no dia do evento);

- intervalo de tempo entre jogos como mandante;

- ações comerciais variadas, como lançamento de uniforme e apresentação de reforço.

Essas variáveis foram geradas combinando dois elementos: estudos prévios sobre o objeto e reuniões com a diretoria do clube, nas quais eram discutidas variáveis que se acreditava terem influência sobre o público. Algumas variáveis apresentam difícil categorização, como o "estilo do jogo" do time ou "raça" da equipe nos jogos. Essas variáveis, diferentes do desempenho em si (vitórias, saldo de gols, etc), apresentam dificuldade na criação de critérios de mensuração e foram excluídas do modelo inicial produzido.

\section{ANÁLISE E DISCUSSÃO DOS RESULTADOS}

A tabela 2 exibe o modelo gerado, com suas variáveis finais. Por motivo de confidencialidade, omitiu-se o nome da variável e os parâmetros estimados foram divididos por uma constante, para que a privacidade do modelo fosse mantida.

O valor do $r^{2}$ obtido apresentou-se bastante satisfatório, com $72,3 \%$ da variância explicada em função das variáveis independentes. Conforme a significância dos parâmetros estimados, adotou-se o critério de tolerância para aceitação do parâmetro estimado de 0,1. Isso porque o resultado com a tolerância de 0,1 foi ligeiramente superior ao obtido com tolerância de 0,05e os parâmetros estimados possuíam 0 sinal esperado. 
Tabela 2 - Modelo de Demanda Gerado

\begin{tabular}{|l|c|c|c|}
\hline Variável & $\beta$ & Sig. & \% de Variação \\
\hline (Constante) & $6.044,2$ &, 000 & - \\
\hline Preço/i & $-1.398,5$ &, 000 & $20,1 \%$ \\
\hline x2 & $1.799,4$ &, 000 & $12,5 \%$ \\
\hline x4 & 27,8 &, 033 & $8,9 \%$ \\
\hline x5 & $-1.913,4$ &, 031 & $13,2 \%$ \\
\hline x6 7 x7 & 697,2 &, 048 & $4,8 \%$ \\
\hline x8 & $-543,5$ &, 005 & $3,8 \%$ \\
\hline x9 & 147,7 &, 000 & $8,2 \%$ \\
\hline Interação entre x2 ex3 (níveis superiores) & $2.348,7$ &, 000 & $16,3 \%$ \\
\hline Interação entre x2 ex3 (níveis inferiores) & 849,1 &, 000 & $5,9 \%$ \\
\hline Interação x3 ex7 (níveis inferiores) & $-501,7$ &, 004 & $3,5 \%$ \\
\hline $\begin{array}{l}\text { Variável Dependente - Público PaganteAjuste } \\
\text { do modelo }\end{array}$ & $-429,8$ &, 074 & $3,0 \%$ \\
R2 0,723 & & \\
\hline
\end{tabular}

No total, onze variáveis foram consideradas significantes para a previsão de público, sendo o preço/i a de maior poder de impacto no público. 0 intervalo de influência dessa variável no público equivale a $20,1 \%$ do potencial das demais variáveis mapeadas. Algumas variáveis mostraram-se significantes apenas na interação com outras variáveis. Um exemplo disso seria o horário da partida. Não há um horário essencialmente "bom" ou "ruim", mas sua combinação com um determinado perfil de campeonato, por exemplo, pode diminuir o público potencial de uma partida.

Inicialmente, foram criadas vinte e quatro categorias de i, de acordo com a competição e fase disputada. O melhor ajuste do modelo ocorreu com doze valores finais de i. Ou seja, há algumas competições e fases cuja relação com o preço influencia de forma similar a demanda de um jogo.

Os resultados obtidos mostram que as premissas adotadas foram válidas na formulação da ferramenta de definição de preços. $O$ valor de $r^{2}$ obtido, essencialmente maior do que em trabalhos verificados anteriormente, como o de Souza (2004) e Benevides et al (2015), mostrou que o preço como variável dependente adiciona poder explicativo relevante na interpretação da demanda dos jogos. Assim, a adoção de uma perspectiva de demanda monopolista mostrou-se bastante válida nesta situação. 
A segunda premissa também permite, a partir da exploração de uma política de preços, a prática de estratégias diferentes de acordo com o momento do clube. Para cada condição de fatores envolvida em uma partida, há preços diferentes que fazem com que a receita máxima seja obtida. Isto é, a receita máxima é obtida com preços diferentes jogo a jogo. Isto sugere que clubes que queiram maximizar público ou renda podem adotar uma precificação dinâmica de seus jogos.

Pindyck e Rubinfeld (2002) mostram que o preço que maximiza o lucro de um monopolista é aquele no qual a receita marginal iguala-se ao custo marginal. Neste caso específico, não se torna necessário a análise do custo marginal para cada nível de preço praticado. Essa particularidade ocorre pela razão do custo variável ser próximo de zero na venda de ingressos. Isto é, os custos envolvidos na comercialização são essencialmente fixos. Nem sequer a impressão do ticket mais é algo representativo, dado o volume de vendas pela internet registrado atualmente (mais de $80 \%$ dos ingressos no clube analisado).

Após a obtenção do modelo exposto na tabela 2, foi iniciado um processo de definição do preço do ingresso com o cenário de receita máxima para cada jogo disputado pela equipe. Nos oito jogos subsequentesà criação do modelo, foram obtidos os resultados expostos no gráfico 3.

Gráfico 3 - Comparação entre público real e previsto

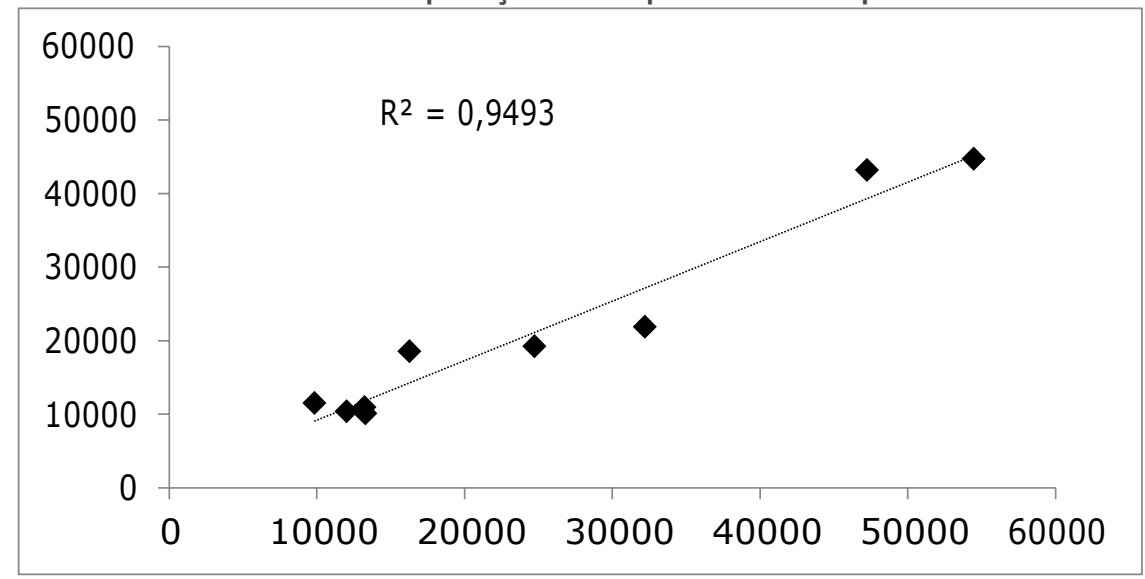


A relação entre público previsto e observado a partir da adoção do modelo de precificação de ingressos mostra que, com a implementação de uma ferramenta analítica, obteve-se uma melhor previsão do público esperado para um jogo. Além disso, nesse intervalo, a variação entre o preço mínimo e máximo foi de $284 \%$, mostrando que o maior excedente possível pode ser capturado com um preço para cada partida.

Os doze valores de i diferentes obtidos, que gerencialmente significam que o clube possui doze produtos diferentes em relação à atração de público ao estádio de acordo com o preço praticado, permitem ao clube a exploração de uma política de preços transparentes ao torcedor. Isto é, conhecendo como a demanda varia de acordo com o preço para cada partida disputada, é possível comunicar ao torcedor com antecedência qual o preço máximo que será cobrado em cada jogo disputado pelo clube ao longo da temporada. Essa prática pode ser um instrumento de minimização da insatisfação com valores altos de ingressos em jogos específicos, já que a queixa recorrente é o aumento súbito dos valores.

Há inúmeros benefícios oriundos de uma melhor previsão de demanda nesse caso. O dimensionamento de serviços de alimentação e bebidas, por exemplo, é um desses benefícios. Com uma previsão de público mais aderente à realidade observada, os parceiros envolvidos no estádio conseguem estabelecer com maior segurança seus estoques, dimensionando produtos e mão de obra de acordo com a demanda projetada pelo clube. O prévio conhecimento de jogos de baixa demanda, por exemplo, facilita a formatação de programas de incentivo sem canibalização de receita. Em jogos de maior demanda, extrai-se maior excedente do público com valores maiores de ingresso.

Outra aplicação bastante prática dessa abordagem é a assertividade de uma escolha de transferência de mando de jogos. Em jogos de baixa demanda, o clube pode optar por transferir o jogo para uma praça com demanda reprimida. Isso tem o potencial de aumentar consideravelmente a 
arrecadação, embora possa gerar insatisfação no público torcedor local. Caberá ao clube o equilíbrio dos trade-offs envolvidos em uma decisão desse tipo. O conhecimento prévio de público potencial para cada jogo em função do preço praticado permite também a criação de pacotes de ingressos que não canibalizem a receita individual de cada jogo. Ou seja, a precificação de pacotes ocorre com menor assimetria de informação.

Outra função da abordagem é a interpretação correta de qual o potencial de arrecadação em função de um melhor desempenho esportivo. Estimando-se corretamente a arrecadação de bilheteria a priori, é possível compreender qual o nível de investimento aceitável no elenco de jogadores para ter um time competitivo. É notório que o desempenho esportivo não depende apenas da qualidade dos jogadores contratados, mas o dimensionamento correto da receita incremental gerada facilita as decisões de investimentos em atletas.

Finalmente, vê-se na metodologia desenvolvida uma ferramenta que dá ao clube a possibilidade de ter uma relação transparente com o público torcedor na comunicação dos preços que serão praticados ao longo da temporada. Ao conhecer previamente os preços, a variação dos valores tende a gerar menos insatisfação em jogos cujo preço será alto. Afinal, não haverá surpresas por parte do torcedor quando o time praticar o preço combinado de forma antecipada.

\section{CONSIDERAÇÕES FINAIS E LIMITAÇÕES DA PESQUISA}

A partir dos resultados obtidos nessa pesquisa, abre-se uma oportunidade para a melhoria de resultados com a captação de variáveis subjetivas por meio da tecnologia. As variáveis indicadas pela diretoria como "raça" e "estilo de jogo" podem ser categorizadas mediante algum esforço de análise de big data, a partir das interações dos torcedores do clube coma instituições em redes de relacionamento. Além da coleta de novas informações para a tentativa de melhora na explicação da variabilidade da demanda, sugere-se também a utilização de novos métodos de previsão. A 
obra de Lantz (2013), que expõe modelos de inteligência artificial, pode inspirar pesquisadores e gestores, mesmo que alguns métodos não estejam suportados por testes estatísticos como um modelo de regressão exposto neste artigo.

Ao adotar a premissa de que clubes são monopolistas de suas demandas, uma das limitações desse estudo está na restrição de sua unidade de análise. Contudo, os resultados alcançados permitem aos gestores e pesquisadores a aplicação de metodologia semelhante em outros clubes, mesmo que para teste de aderência da metodologia exposta nesse trabalho em outras instituições que se enquadrem nessas características.

\section{REFERÊNCIAS BIBLIOGRÁFICAS}

Alvito, M. (2006). A parte que te cabe neste latifúndio: o futebol brasileiro e a globalização. Análise Social, 41, 451-474.

Barney, J.B.; Hesterly, W.S.; Rosemberg, M. (2007). Administração estratégica e vantagem competitiva. São Paulo: Pearson.

Benevides, B.I.L.; Santos, S.M.; Cabral, A.C.A.; Ribeiro, R.A.; Holt, N.L.S. (2015). Demanda por Futebol no Brasil e na Inglaterra. Revista Pensamento Contemporâneo em Administração, v(2), 96-112.

Damatta, R. (1994). Antropologia do Óbvio: Notas em Torno doSignificado Social do Futebol Brasileiro. Revista da USP, 22, 10-17.

Damo, A. (2018). Futebóis - da horizontalidade epistemológica à diversidade política. Revista FuLiA / UFMG, 3(3), 37-66.

Deloitte (2011). Muito além do futebol: Estudo sobre esportes no Brasil.

Deloitte. (2019). Captains of Industry: Football Money League.

Ekelund, P. (1998). A Rentabilidade das Associações de Times de Futebol: os exemplos das ligas de Futebol da Itália e da Inglaterra. Anais do Congresso Internacional EAESP de Gestão de Esportes, São Paulo, 1. 
Farris, P.W.; Bendle, N.T.; Pfeifer, P.R.; Reibstein, D.J. (2012). Métricas de Marketing. Porto Alegre: Bookman.

Ferguson, C.E. (1999). Microeconomia (20 ed). Rio de Janeiro: Forense Universitária.

Fujita, L. (2018). Qual é o esporte mais praticado no Brasile Super Interessante, Recuperado em 10 maio de 2019, de https://super.abril.com.br/mundo-estranho/qual-e-oesporte-mais-praticado- no-brasil/

Globo Esporte. (2013). Setores Mais Caros deixam vazio na volta de Flu e Vasco ao Maracanã. Globo Esporte, Recuperado em 10 maio 2019, de http://globoesporte.globo.com/futebol/brasileirao-seriea/noticia/2013/07/setores-mais-caros-deixam-vazio-na-volta-de-flu-e-vasco- aomaracana.html.

Globo Esporte. (2018). Ingresso mais caro diminui público e faz Palmeiras lucrar só R\$ 81 mil a mais do que no seu jogo com mais torcida no ano, Recuperado em 10 maio 2019, de https://globoesporte.globo.com/futebol/times/palmeiras/noticia/compensou -ingresso-mais-caro-diminui-publico-e-faz-palmeiras-lucrar-r-81-mil.ghtml.

Globo Esporte. (2018). Botafogo, mais eficiente, vence e afunda o Atlético-PR no Z-4, Recuperado em 10 maio 2019, de https://globoesporte.globo.com/rj/futebol/brasileirao-serie-a/jogo/13-062018/botafogo-atletico-pr.ghtml.

Hunt, K.A., Bristol, T., \& Bashaw, R.E. (1999). A conceptual approach to classifying sports fans. Journal of Services Marketing, 13(6), 439-452.

Itaú BBA. (2018). Análise Econômico-Financeira dos Clubes de Futebol Brasileiros | 2018.

Itaú BBA. (2020). Análise Econômico-Financeira dos Clubes de Futebol Brasileiros | 2018. 
Kotler, P.; Keller, K.L. (2012). Marketing Management. Ney York: Prentice Hall.

Lantz, B. (2013). Machine Learning with R. Packt Publishing.

Lemos, F.O. (2006). Metodologia para Seleção de Métodos de Previsão de Demanda. Dissertação de Mestrado, Universidade Federal do Rio Grande do Sul, Porto Alegre, Brasil.

McAfee, R. P. (2002). Competitive Solutions. New Jersey: Princeton University Press.

Pindyck, R.S \& Rubinfeld, D. L. (2002). Microeconomia. São Paulo: Prentice Hall.

Porter, M. E. (2004). Estratégia competitiva. Elsevier Brasil.

Ribeiro, R. (2017). Desenvolvimento de Recursos para o Desempenho Superior: Uma Análise sobre os Fatores Determinantes para o Aumento de Torcida em um Clube de Futebol. Tese de Doutorado, Universidade de São Paulo, São Paulo, Brasil

Ribeiro, R., Polo, E.F. Kusters, D., \& Pilli, L.E. (2014). Um título estadual ou uma classificação para a Copa Libertadores? Um estudo sobre o desempenho esportivo na satisfação dos torcedores de grandes clubes brasileiros. Anais do Simpósio Internacional de Estudos Sobre o Futebol, São Paulo, 2.

Ribeiro, R.; Kusters, D.; Polo, E.F.; Homenko Neto, A. \& Crocco, L. (2015). Demanda em jogos de futebol: um estudo sobre influências situacionais e atributos da partida na intenção de compra do torcedor. Eletronic Journal of Economic Sociology Studies, 5(3), 518-531.

Rodrigues, F.X.F. (2010). O fim do passe e as transferências de jogadores Brasileiros em uma época de globalização. Sociologias, 12(24), 338-380.

Sampron, D.A. (2005). Seleção de Técnicas de Previsão de Mercado Segundo as Diferentes Categorias de Novos Produtos. RAE Eletrônica, 4(2). 
Slack, N.; Chambers, S.; Johnston, R. (2009). Administração da Produção. São Paulo: Atlas..

Souza, F.A.P. (2004). Um Estudo sobre a Demanda por Jogos de Futebol nos Estádios Brasileiros. 2004. Dissertação de Mestrado, Universidade de São Paulo, São Paulo, Brasil. 